\title{
Determination and Comparison of the Lipid Profile and Sodium Content of Gluten-Free and Gluten-Containing Breads from the Spanish Market
}

\author{
Alba Tres ${ }^{1,2}$ - Natalia Tarnovska ${ }^{1}$ - Elisa Varona ${ }^{1,2} \cdot$ Beatriz Quintanilla-Casas $^{1,2} \cdot$ Stefania Vichi $^{1,2} \cdot$ Anna Gibert $^{3}$. \\ Elisenda Vilchez ${ }^{3}$. Francesc Guardiola ${ }^{1,2}$ iD
}

Published online: 2 June 2020

(C) The Author(s) 2020

\begin{abstract}
The objective is to verify if gluten-free $(\mathrm{GF})$ and gluten-containing $(\mathrm{G})$ breads differ in their sodium content and lipid profile. Samples of GF $(n=20)$ and G $(n=14)$ sliced white sandwich bread of commercial brands most frequently consumed in Spain were collected. The fatty acid (FA) composition and the contents of sodium, fat, cholesterol and phytosterols were determined. Sodium, fat and cholesterol contents were significantly higher in GF bread. The FA composition also differed, while G breads declared in most instances the use of sunflower oil as fat ingredient and presented a higher polyunsaturated FA percentage; GF breads declared a wide variety of fats and oils as ingredients (coconut, palm, olive, sunflower, etc.) which was reflected in their FA profile. Cholesterol content was higher in GF bread because five samples declared the use of whole egg, while G samples did not include any egg product in their formulas. Phytosterol content was higher in G bread but its variability was greater in GF bread. In conclusion, nutritional quality of GF bread varied depending on the ingredients used and might be lower than that of $\mathrm{G}$ bread. However, these differences in composition could be reduced or eliminated through changes in the formulation of GF bread. Moreover, the comparison of the results obtained in our laboratory for fat and salt content with the declared contents on the labels showed a much higher deviation for GF samples and it can be concluded that the quality of the nutritional information declared was lower in GF samples.
\end{abstract}

Keywords Fatty acid composition · Fat, cholesterol, phytosterol and sodium content · Gluten-free bread · Nutritional value

Electronic supplementary material The online version of this article (https://doi.org/10.1007/s11130-020-00828-w) contains supplementary material, which is available to authorized users.

Francesc Guardiola

fguardiola@ub.edu; https://orcid.org/0000-0002-8624-8749

1 Nutrition, Food Science and Gastronomy Department-XaRTA, Torribera Food Science Campus, Faculty of Pharmacy and Food Science, Universitat de Barcelona, Av. Prat de la Riba, 171, 08921 Santa Coloma de Gramenet, Spain

2 Institut de Recerca en Nutrició i Seguretat Alimentària, Universitat de Barcelona, Av. Prat de la Riba, 171, 08921 Santa Coloma de Gramenet, Spain

3 Associació de Celíacs de Catalunya, Carrer de la Independència, 257, 08026 Barcelona, Spain

$\begin{array}{ll}\text { Abbreviations } \\ \text { CD } & \text { Coeliac disease } \\ \text { CVD } & \text { Cardiovascular disease } \\ \text { DW } & \text { Dry weight } \\ \text { FA } & \text { Fatty acids } \\ \text { G } & \text { Gluten-containing } \\ \text { GC } & \text { Gas-chromatography } \\ \text { GF } & \text { Gluten-free } \\ \text { GFD } & \text { Gluten-free diet } \\ \text { ICP-OES } & \text { Inductively coupled plasma optical } \\ & \text { emission spectroscopy } \\ \text { MUFA } & \text { Monounsaturated fatty acids } \\ \text { PCA } & \text { Principal component analysis } \\ \text { PUFA } & \text { Polyunsaturated fatty acids } \\ \text { SFA } & \text { Saturated fatty acids } \\ \text { WW } & \text { Wet weight }\end{array}$




\section{Introduction}

Coeliac people represent about $1 \%$ of the European population [1]. Coeliacs must adhere to a strict gluten-free diet (GFD) for life. However, there is an increasing number of people who follow a GFD without medical prescription. In addition, not many studies have investigated the nutritional effects of the GFD on healthy populations.

Moreover, some studies carried out in some countries around the world (including Spain) using information from food labels and/or from food databases showed significant composition differences between gluten-free foods and their equivalents with gluten [2-11]. As the nutritional evaluation carried out in these studies indicated that nutritional quality of gluten-free (GF) products was lower or equivalent to that of the gluten-containing $(\mathrm{G})$ products, some authors do not recommend the consumption of GF products unless there is clear evidence of gluten intolerance [9, 11]. In addition, some of these studies also recently observed that the availability of GF products on the market is still lower than that of their $\mathrm{G}$ counterparts $[2,4]$ and that their cost is higher $[2,4-6,8]$. Therefore, much research is needed to reformulate GF products and specially GF bakery products in order to improve the nutritional quality, organoleptic characteristics and consumer acceptance of the GF products present in the market $[9,12$, 13].

Although several studies have found differences between the nutritional quality of GF and G products based on the labeling information, to date there are no studies in the literature that make this comparison based on the analytical results obtained from a representative market sample. Thus, to verify that these differences exist in the market, GF and G sliced white sandwich bread of commercial brands most frequently consumed in Spain were collected from local and online supermarkets and analyzed in our laboratory. The study was focused on bread because it is the most consumed GF food in Europe [14], even slightly overcoming pasta in Italy. Also, according to our previous bibliographic study, bread was the product that could present more differences in composition [10]. In addition, GF sliced white sandwich bread accounts for the 85-90\% of the bread consumed by coeliacs in Spain and its gluten-containing equivalents are clearly defined and identified in the market.

Fatty acid (FA) profile and contents in fat, sodium, cholesterol and phytosterols were determined in the samples. These compositional parameters have been chosen because they are dietary factors nutritionally related with cardiovascular health. In fact, there is a controversy about if coeliac disease (CD) can predispose to cardiovascular disease (CVD) or not. On one hand, there are studies that seemed to confirm it $[15,16]$ but others obtained opposite results [17]. In addition, the recent systematic reviews and meta-analysis about this point $[18,19]$ concluded that $\mathrm{CD}$ could be associated to a small increase in risk for developing CVD, but the evidence base is limited and there is a need for adequately powered prospective studies with appropriate adjustment for potentially confounding factors. Another controverted aspect is the effect of the GFD on the risk of CVD in coeliacs. Some studies indicate that GFD decrease the risk [20]; while others [21] conclude that GFD does not affect this risk. A systematic review on this aspect [22] concludes that GFD alters certain cardiovascular risk factors in patients with $\mathrm{CD}$, but the overall effect on cardiovascular risk is unclear and needs further comprehensive and well controlled studies. In addition, there is an even less studied and more controverted question: the effect of the GFD on CVD risk in individuals without diagnosed CD [23, 24], but the evidence at this moment indicates that GFD should be discouraged among people without $\mathrm{CD}$.

The objective of this study is to compare the nutritional value of commercial sliced white sandwich bread with and without gluten, specifically with reference to its FA profile and contents in fat, sodium, cholesterol and phytosterols. In addition, the relationship between our analytical results and the list of ingredients declared on the label was studied in order to identify how the different ingredients can contribute to the composition differences found between the samples. Finally, our analytical results have been compared with the nutrition facts declared on the labels in order to assess the quality of the nutritional information provided to the consumer.

\section{Materials and Methods}

\section{Sample Preparation}

Samples of G $(n=14)$ and GF $(n=20)$ bread from the commercial brands most frequently consumed in Spain were collected between June and July 2017 from local and online supermarkets. All samples selected were of white sliced sandwich bread type (without any seeds or nuts). The sampling covered a market share of $85-90 \%$ for samples with gluten and of $87 \%$ for samples without gluten (for further information see supplementary material).

Two bags of bread of each sample were purchased. For each sample, $200 \mathrm{~g}$ (100 g from each bag) were taken, bread slices with a similar proportion of crumb and crust were taken from different positions of each bag. For all samples, no slices were taken from the ends of the bread, since a highly variable proportion of crust between samples could have affected the results. The $200 \mathrm{~g}$ of each sample were homogenized two times for $20 \mathrm{~s}$ at $3000 \mathrm{rpm}$ using a knife mill (Robot Coupe Blixer 2, Vincennes, France), then packed in 7 multilayer bags (Cryovac BB325, Sealed Air SL, Sant Boi de Llobregat, Spain) and stored at $-20{ }^{\circ} \mathrm{C}$ until analysis. 


\section{Analytical Determinations}

All analytical determinations were carried out in duplicate. Determination of moisture was carried according to the 925.10 AOAC method. Determination of the sodium content was conducted by inductively coupled plasma optical emission spectroscopy (ICP-OES). Determination of fat content was carried using an adaptation of the 922.06 AOAC method. Determination of the FA composition was carried by gaschromatography (GC) after methylation of the lipid extract. Determination of the content of cholesterol and phytosterols was carried by GC after silylation of the unsaponifiable matter. For references and a detailed description of the analytical methods see supplementary material.

\section{Labeling Information}

The declared nutritional information of all samples was recorded, analyzed and compared with the analytical results when possible. The ingredients were also recorded and a detailed list of the ingredients of each sample was prepared (supplementary material).

\section{Statistical Analysis}

The average of all analytical duplicates was calculated and these results were used for statistical analysis.

To explore clustering of samples, a principal component analysis (PCA) was conducted with the results of all the parameters determined. The clustering was studied according to the gluten content of the samples and also according to the fats and oils declared in the list of ingredients of the samples. The PCA was carried using the SIMCA software (v13.0, Umetrics AB, Umeå, Sweden). The data was also represented for each parameter and for each type of bread (with and without gluten) using box plot diagrams (supplementary material).

The normality of the variables (determined in our laboratory and obtained from labeling) was checked using the Shapiro-Wilk test. As in some cases the variables did not follow a normal distribution, non-parametric tests (MannWhitney $\mathrm{U}$ ) were used to compare the composition of $\mathrm{G}$ and GF bread. In all cases, the values of $p<0.05$ were considered significant. The IBM SPSS Statistics software (v23.0, IBM, Armonk, NY) was used to carry these tests.

\section{Results and Discussion}

In all samples, moisture, FA composition and contents of sodium, fat, cholesterol and phytosterols were determined. Results for each sample are shown in Tables S1 and S2 (supplementary material).
Moisture data were used to express the contents of sodium, fat, cholesterol and phytosterols in dry weight (DW) basis. Since the differences between the results obtained for $\mathrm{G}$ and GF bread showed similar statistical significance regardless of whether the results were expressed on wet weight (WW) or DW basis (Table 1), we will here comment only the results on WW because they are more interesting for the consumers. Only in one GF bread sample (GF 5) the moisture value (45.58\%, Table S2) slightly exceeded the maximum value allowed for special breads by the Spanish legislation in 2017 (sampling dates), which was $40 \%$ for $\mathrm{G}$ sliced white sandwich bread and $45 \%$ for GF sliced white sandwich bread. From July 1st 2019, there are no moisture limits for these breads in the Spanish legislation. For legislation references see supplementary material.

The clustering of the samples obtained through the PCA (Fig. 1) showed a much greater variability in the composition of the GF bread samples than that of G samples.

\section{Sodium Content}

Sodium content of GF bread was higher and more variable than that of $\mathrm{G}$ bread (Table 1). The values of $\mathrm{G}$ group ranged from 0.34 to $0.57 \mathrm{~g} \mathrm{Na} / 100 \mathrm{~g}$ and the values of GF samples from 0.28 to $0.75 \mathrm{~g} \mathrm{Na} / 100 \mathrm{~g}$ on WW. Thus, in the GF group there were both the highest (GF 7) and the lowest (GF 5) sodium content samples (Table S2).

\section{Fat Content}

GF bread samples showed more variable fat content (from 1.5 to $7.8 \mathrm{~g} / 100 \mathrm{~g} \mathrm{WW}$ ) than their equivalents with gluten (from 1.5 to $3.1 \mathrm{~g} / 100 \mathrm{~g} \mathrm{WW}$ ). The median of fat content was significantly higher in GF samples (Table 1).

\section{Fatty Acid Composition}

The FA composition of GF bread was also more variable than that of G bread, both in terms of saturated (SFA), monounsaturated (MUFA) and polyunsaturated FA (PUFA) (Table 2 and Fig. S1 in supplementary material).

The FA composition of a product such as sandwich bread depends primarily on the FA composition of the fats and oils added in its preparation, although the lipids contained in other ingredients also have a certain influence (see supplementary material for the complete list of ingredients of each sample, Tables S3 and S4). The GF samples showed a higher variability in FA composition because G samples declared only sunflower and soybean oil in their list of ingredients, while GF samples declared a variety of fats and oils (coconut, palm, olive, sunflower or soybean oils, among others) with different FA composition [25], which obviously influenced the FA composition of the final product (Fig. 2 and Table 2). In fact, 
Table 1 Contents in fat, sodium, cholesterol and phytosterols in gluten-containing and gluten-free samples

\begin{tabular}{|c|c|c|c|c|c|c|}
\hline & & \multicolumn{2}{|c|}{ Gluten-containing $(n=14)$} & \multicolumn{3}{|c|}{ Gluten-free $(n=20)$} \\
\hline & & Mean \pm SD & Median & Mean \pm SD & Median & $P^{*}$ \\
\hline \multirow[t]{8}{*}{ Wet weight (WW) } & Sodium (g/100 g WW) & $0.44 \pm 0.08$ & 0.41 & $0.54 \pm 0.13$ & 0.52 & 0.020 \\
\hline & Fat $(\mathrm{g} / 100 \mathrm{~g} \mathrm{WW})$ & $2.0 \pm 0.52$ & 1.7 & $3.6 \pm 1.57$ & 3.9 & $<0.001$ \\
\hline & Cholesterol (mg/100 g WW) & ND & ND & $5.8 \pm 10.37$ & $\operatorname{tr}$ & 0.003 \\
\hline & Campesterol (mg/100 g WW) & $3.7 \pm 0.48$ & 3.9 & $2.2 \pm 1.36$ & 1.8 & $<0.001$ \\
\hline & Stigmasterol (mg/100 g WW) & $0.3 \pm 0.52$ & $\operatorname{tr}$ & $1.1 \pm 1.38$ & 1.1 & 0.043 \\
\hline & $\beta$-Sitosterol (mg/100 g WW) & $17.1 \pm 2.37$ & 17.0 & $10.3 \pm 6.95$ & 8.1 & $<0.001$ \\
\hline & Sitostanol (mg/100 g WW) & $2.8 \pm 0.29$ & 2.8 & $0.9 \pm 0.93$ & 1.0 & $<0.001$ \\
\hline & Total phytosterols (mg/100 g WW) & $23.8 \pm 3.34$ & 23.6 & $14.5 \pm 10.24$ & 11.3 & $<0.001$ \\
\hline \multirow[t]{8}{*}{ Dry weight (DW) } & Sodium (g/100 g DW) & $0.69 \pm 0.12$ & 0.64 & $0.89 \pm 0.18$ & 0.87 & 0.003 \\
\hline & Fat $(\mathrm{g} / 100 \mathrm{~g} \mathrm{DW})$ & $3.1 \pm 0.78$ & 2.7 & $5.9 \pm 2.66$ & 6.5 & $<0.001$ \\
\hline & Cholesterol (mg/100 g DW) & ND & ND & $9.3 \pm 16.88$ & $\operatorname{tr}$ & 0.003 \\
\hline & Campesterol (mg/100 g DW) & $5.7 \pm 0.74$ & 6.0 & $3.6 \pm 2.36$ & 2.9 & $<0.001$ \\
\hline & Stigmasterol (mg/100 g DW) & $0.4 \pm 0.80$ & $\operatorname{tr}$ & $1.8 \pm 2.38$ & 1.7 & 0.039 \\
\hline & $\beta$-Sitosterol (mg/100 g DW) & $26.7 \pm 3.42$ & 26.5 & $17.1 \pm 11.80$ & 13.7 & 0.001 \\
\hline & Sitostanol (mg/100 g DW) & $4.4 \pm 0.43$ & 4.4 & $1.5 \pm 1.51$ & 1.7 & $<0.001$ \\
\hline & Total phytosterols (mg/100 g DW) & $37.2 \pm 4.87$ & 36.9 & $24.0 \pm 17.43$ & 19.1 & $<0.001$ \\
\hline
\end{tabular}

${ }^{*} P$-values for median comparisons between gluten-containing and gluten-free samples according to Mann-Whitney U test

$N D$ not detected, $t r$ traces (content between the limits of detection and quantification)

in Fig. 2 it can be observed how, in general, the samples tended to be grouped according to the type of declared fat, although there were some exceptions. For instance, two samples exclusively declared sunflower oil, but appeared very separated from the rest of the samples containing sunflower oil and close to samples that used saturated fats (upper right area of Fig. 2a, GF 19 and 20).

When comparing the $G$ and GF bread, significant differences in the total of MUFA and PUFA were found (Table 2). The G samples showed lower content in MUFA and a higher content in PUFA $n-6$ and PUFA $n-3$, in the three cases mainly due to the differences in the main FA of these groups, respectively, oleic, linoleic and linolenic acid.
The content of oleic, linoleic and linolenic acids for bread samples, in general, varied according to the fat or oil used in the formulation (see Fig. S2 for GF samples in supplementary material). For example, the GF samples that declared olive oil as an ingredient had values close to $70 \%$ of oleic acid (C18:1 $n-9)$ and low values of linoleic acid (C18:2 n-6). Also, the GF sample that declared soybean oil (GF 3) among its ingredients was the one with the highest \% of linolenic acid (C18:3n-3) (Fig. S2c).

Regarding the GF samples that only declared sunflower oil as added fat, in general, these samples showed the highest values of linoleic acid (C18:2 n-6) (Fig. S2b) and relatively low values of oleic (C18:1 n-9) (Fig. S2a). However, it should

Fig. 1 Scores plot from principal component analysis on fat, sodium, sterols and fatty acid profile data (expressed as wet weight, data mean centered and scaled to the unit of variance) from gluten-containing $(n=14$, orange) and gluten-free ( $n=20$, green) white sandwich breads

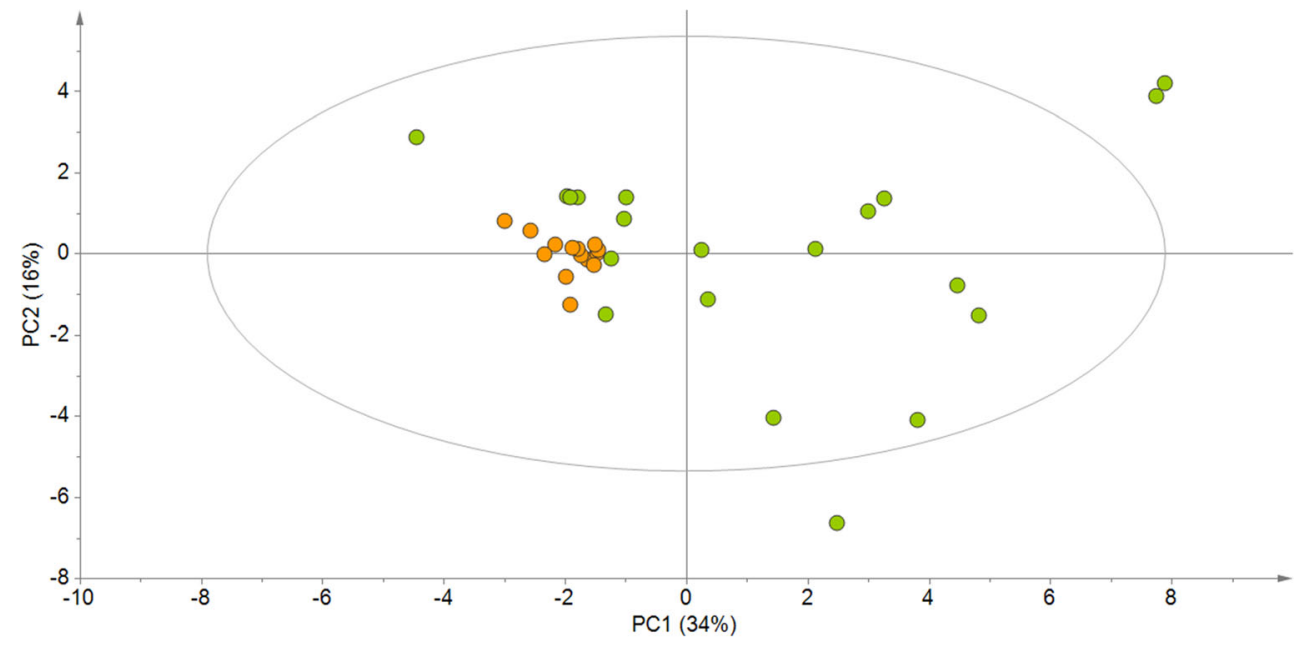


Table 2 Fatty acid profile of gluten-containing $(n=14)$ and gluten-free $(n=20)$ white sandwich bread, results expressed as $\%$ coming from area normalization

\begin{tabular}{|c|c|c|c|c|c|}
\hline \multirow[t]{2}{*}{ Fatty acid (\%) } & \multicolumn{2}{|c|}{ Gluten-containing $(n=14)$} & \multicolumn{3}{|c|}{ Gluten-free $(n=20)$} \\
\hline & Mean \pm SD & Median & Mean \pm SD & Median & $P^{*}$ \\
\hline C6:0 & $<0.01 \pm 0.02$ & ND & $<0.1 \pm 0.02$ & ND & 0.269 \\
\hline C8:0 & $<0.01 \pm 0.01$ & ND & $0.1 \pm 025$ & $<0.1$ & 0.013 \\
\hline C10:0 & ND & ND & $0.1 \pm 0.20$ & $<0.01$ & 0.015 \\
\hline $\mathrm{C} 12: 0$ & $<0.1 \pm 0.03$ & $<0.1$ & $0.7 \pm 1.51$ & $<0.1$ & 0.422 \\
\hline $\mathrm{C} 14: 0$ & $0.2 \pm 0.05$ & 0.2 & $0.6 \pm 0.82$ & 0.1 & 0.152 \\
\hline $\mathrm{C} 15: 0$ & $<0.1 \pm 0.02$ & $<0.1$ & $<0.1 \pm 0.02$ & $<0.1$ & 0.802 \\
\hline $\mathrm{C} 16: 0$ & $13.5 \pm 2.16$ & 13.8 & $18.3 \pm 14.24$ & 10.6 & 0.286 \\
\hline $\mathrm{C} 17: 0$ & $<0.1 \pm 0.03$ & $<0.1$ & $0.1 \pm 0.04$ & 0.1 & 0.920 \\
\hline C18:0 & $8.2 \pm 2.71$ & 7.6 & $5.0 \pm 1.81$ & 4.5 & $<0.001$ \\
\hline C20:0 & $0.3 \pm 0.05$ & 0.3 & $0.3 \pm 0.08$ & 0.3 & 0.527 \\
\hline $\mathrm{C} 22: 0$ & $0.6 \pm 0.06$ & 0.6 & $0.5 \pm 0.27$ & 0.4 & 0.641 \\
\hline $\mathrm{C} 24: 0$ & $0.3 \pm 0.03$ & 0.3 & $0.2 \pm 0.09$ & 0.2 & 0.125 \\
\hline Total SFA & $23.2 \pm 4.73$ & 23.1 & $25.9 \pm 17.27$ & 16.3 & 0.134 \\
\hline $\mathrm{C} 16: 1 n-7$ & $0.2 \pm 0.06$ & 0.3 & $0.4 \pm 0.31$ & 0.3 & 0.689 \\
\hline $\mathrm{C} 18: 1 n-9$ & $24.3 \pm 8.63$ & 21.3 & $41.4 \pm 19.88$ & 30.9 & $<0.001$ \\
\hline $\mathrm{C} 18: 1 n-7$ & $0.7 \pm 0.07$ & 0.7 & $1.0 \pm 0.52$ & 0.8 & 0.194 \\
\hline $\mathrm{C} 20: 1 n-9$ & $0.3 \pm 0.04$ & 0.2 & $0.2 \pm 0.08$ & 0.2 & 0.009 \\
\hline Total MUFA & $25.5 \pm 8.66$ & 22.5 & $43.1 \pm 20.52$ & 32.4 & $<0.001$ \\
\hline $\mathrm{C} 18: 2 n-6$ & $50.3 \pm 8.27$ & 53.2 & $30.6 \pm 21.15$ & 20.5 & 0.053 \\
\hline $\mathrm{C} 20: 4 n-6$ & $<0.1 \pm 0.03$ & $<0.1$ & $<0.1 \pm 0.04$ & ND & 0.071 \\
\hline Total $n$-6 PUFA & $50.3 \pm 8.27$ & 53.2 & $30.6 \pm 21.15$ & 20.5 & 0.057 \\
\hline $\mathrm{C} 18: 3 n-3$ & $1.0 \pm 0.19$ & 1.0 & $0.4 \pm 0.31$ & 0.2 & $<0.001$ \\
\hline Total $n$-3 PUFA & $1.0 \pm 0.19$ & 1.0 & $0.4 \pm 0.31$ & 0.2 & $<0.001$ \\
\hline Ratio $n-6 / n-3$ & $54.1 \pm 17.32$ & 51.0 & $147.0 \pm 152.3$ & 85.8 & 0.162 \\
\hline Total PUFA & $51.3 \pm 8.25$ & 54.3 & $31.0 \pm 21.05$ & 20.7 & 0.028 \\
\hline C18:1 trans & $<0.01 \pm 0.01$ & ND & $0.1 \pm 0.09$ & ND & 0.010 \\
\hline
\end{tabular}

${ }^{*} P$-values for median comparisons between gluten-containing and gluten-free samples according to MannWhitney U test

ND not detected, SFA saturated fatty acids, MUFA monounsaturated fatty acids, PUFA polyunsaturated fatty acids. The FA were quantified by peak area normalization (the quantitative results are obtained by expressing the area of a given peak as a percentage of the sum of the areas of all the identified peaks) be noted that four GF samples that only declared sunflower oils as added fats did not follow this pattern. Two of these GF samples (GF 11 and 16) had abnormally high oleic acid (C18:1 n-9) levels and abnormally low linoleic acid (C18:2 $n$-6) levels compared to the usual FA profile of the sunflower oil [25], being their FA profile more similar to samples that declare olive oil. In fact, the FA composition of these two samples seemed to indicate that the added fat might not correspond to sunflower oil, but to an oil (or oil mixture) much richer in oleic acid and much less richer in linoleic acid, such as high-oleic sunflower oil or olive oil [25], among others. The other two GF samples that did not follow the typical FA profile of samples with only sunflower oil were GF 19 and GF 20. These samples showed lower linoleic acid values compared to the FA profile of sunflower oil and higher SFA (C12:0, C14:0, C16:0 and C18:0) values, particularly for palmitic acid (C16:0) (Figs. S2b, S4 and S5). The \% of palmitic acid in these two samples ranged 46-48\%, which could indicate the addition of a palmitic-rich fat such as palm oil instead of sunflower oil. These two last samples corresponded to two different brands, but came from the same producer. Thus, for some GF samples it was observed that the composition in FA was not fully explained by the type of oils declared as ingredients, which could be due to some labeling mistake.

In addition, looking at the FA composition of GF 4 that declared vegetable margarine without specifying the oils that it included, we can see that its C16:0 content was $32.8 \%$, and 
Fig. 2 Principal components analysis on fat, sodium, sterols and fatty acid profile data (expressed as wet weight, data mean centered and scaled to the unit of variance) from glutencontaining $(n=14)$ and glutenfree $(n=20)$ white sandwich breads: (a) scores plot colored according to the type of fat declared in the list of ingredients; (b) Loadings plot of variables
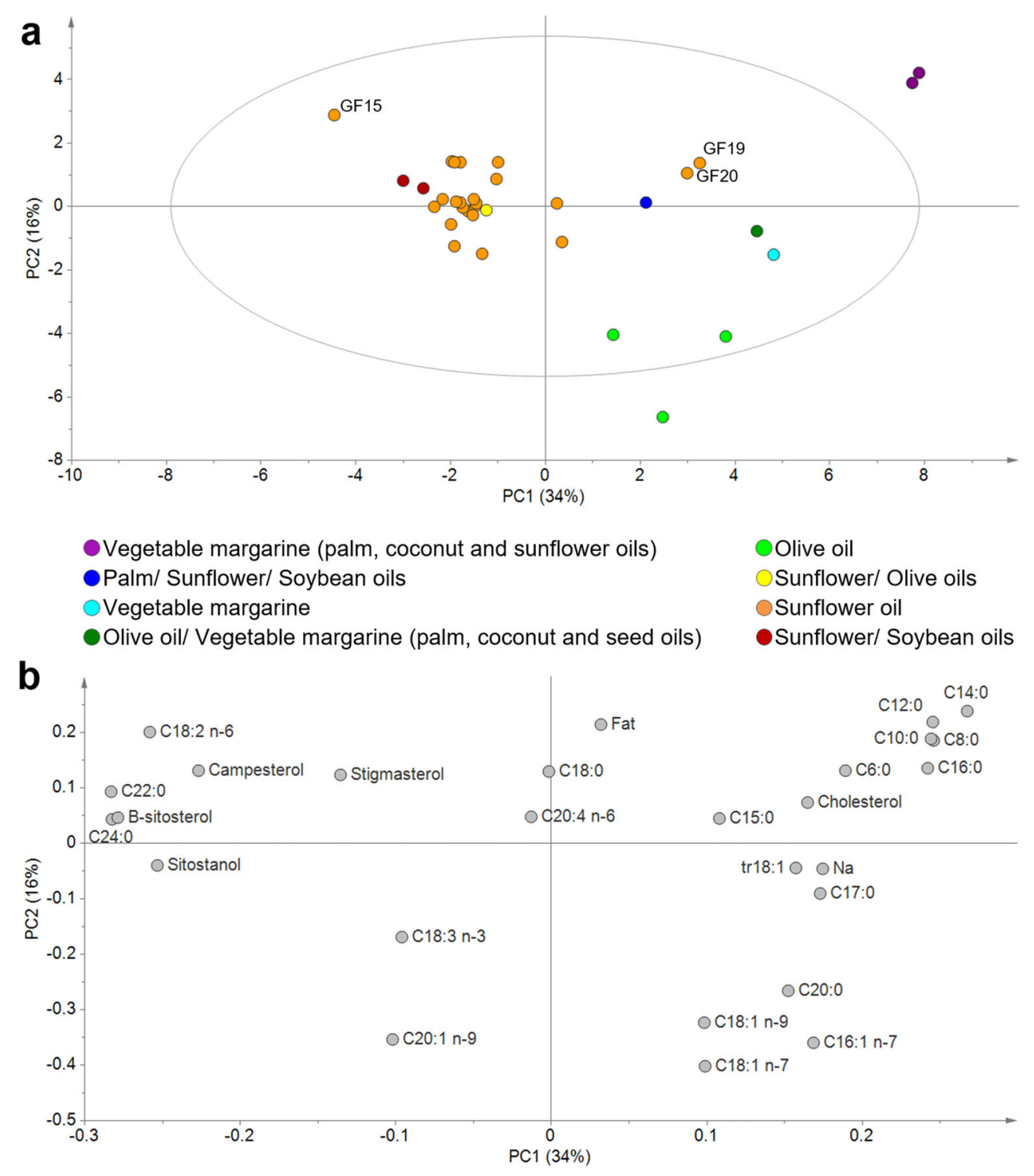

thus comparable to that of the GF 1-3 samples that include palm oil in their list of ingredients (Fig. S5a). Therefore, it is very likely that this margarine contained this saturated fat among its ingredients.

On the other hand, the total SFA did not show significant differences between G and GF bread (Table 2). But, after observing the detailed profile of the various SFA, there were some significant differences in two medium-chain SFA, C8:0 and C10:0 (Table 2). Although these FA were found in low proportions, the median was higher in GF bread than in $G$ bread. Out of 20 GF samples, GF 1, GF 2 and GF 5 presented the highest values of these FA (Fig. S3), as well as for C12:0 and C14:0 (Fig. S4). These three samples were the only ones that declared the use of coconut oil in their formulation, a fat that is richer in medium-chain SFA, especially in lauric acid (C12:0), than the other commonly used fats [25]. Due to this fact, the means for these FA in the GF group were higher, although the differences for the medians of C12:0 and C14:0 were not significant. As example, to show the magnitude of the difference, GF 1 showed $0.78 \%$ of $\mathrm{C} 8: 0,0.60 \%$ of $\mathrm{C} 10: 0$, $4.58 \%$ of $\mathrm{C} 12: 0$ and $2.57 \%$ of $\mathrm{C} 14: 0$, while in the rest of $\mathrm{G}$ and GF samples without coconut oil in their formulation the sum of these four FA was always lower than $1.5 \%$.

The case of stearic acid (C18:0) also deserves a special comment because together with the $\mathrm{C} 8: 0$ and $\mathrm{C} 10: 0$, they were the three SFA that presented significant differences between the two types of bread. The values of stearic acid (C18:0) were lower in GF samples (Table 2), even if samples of the two types that declared only the use of sunflower oil were compared ( $\mathrm{G}$ samples: median $=7.7, n=12$; GF samples: median $=4.6, n=11 ; P<0.001)$. Therefore, it is possible that other ingredients than fats and oils used in bread had an influence on the values of this FA. Analyzing the list of ingredients (Tables S3 and S4), it can be observed that all samples 
of $\mathrm{G}$ bread $(n=14)$ used sodium stearoyl-2-lactylate (E-481) as emulsifier, which is a source of stearic acid, whereas this additive was present only in one of the GF samples (which was not included in the previous comparison because this sample used a mixture of sunflower and extra virgin olive oils).

\section{Cholesterol Content}

Among the samples included in the study, cholesterol was detected only in some GF samples. Thus, the content of cholesterol in GF bread was more variable and significantly higher than in G bread (Table 1 and Fig. S6).

The highest cholesterol values were between 15 and $30 \mathrm{mg} /$ $100 \mathrm{~g}$ of bread and were found in five GF samples (Table S2 and Fig. S7). These five samples were the only ones that declared the use of whole egg in the list of ingredients (see supplementary materials for the complete list of ingredients of each sample, Tables S3 and S4), and this can explain their higher cholesterol content because this ingredient is very rich in this substance [26].

Another sample (GF 15), that presented $2.2 \mathrm{mg}$ cholesterol/ $100 \mathrm{~g}$ of bread, declared the use of egg white (Fig. S7). Since cholesterol is located in the egg yolk, but not in the egg white, this cholesterol content could come from small amounts of egg yolk in the used egg white.

Finally, there were traces of cholesterol in some GF samples that declared the use of egg albumin, skim milk or milk proteins in the list of ingredients (Tables S2 and S4). Cholesterol was not detected in any G sample (Table S1) because only one $\mathrm{G}$ sample (G 1) declared an ingredient from animal origin (whey powder) (Table S3).

Therefore, it is clear that the difference in cholesterol content existed due to the type of ingredients used in bread formulation.

Which has a certain relevancy in terms of cholesterol content, was the fact that the five GF samples that used whole egg (Fig. S7) showed a relatively high cholesterol content (between 15 and $30 \mathrm{mg} / 100 \mathrm{~g} \mathrm{WW}$ ) and $100 \mathrm{~g}$ of these breads (between 3 and 5 bread slices) were equivalent in terms of cholesterol content to $150-300 \mathrm{~g}$ of whole milk or to $27-$ $54 \mathrm{~g}$ of pork chop or pork fillet [26]. In addition, it must be considered that among these five GF samples having the highest levels of cholesterol, three of them (GF 1, GF 2 and GF 4) are among the five GF samples having the highest SFA proportions (Table S2).

\section{Phytosterol Content}

Phytosterols such as campesterol, stigmasterol, $\beta$-sitosterol and sitostanol were detected and quantified. Unlike cholesterol, all of them were found in both groups of samples. The medians of campesterol, $\beta$-sitosterol and sitostanol were significantly higher in $\mathrm{G}$ bread, while stigmasterol was higher in GF bread (Table 1). As for other parameters, the variability in the content of phytosterols was greater in GF breads (Table 1 and Fig. S8), because the ingredients used in their formulas were more numerous and variable.

Taking into account the type of fat declared in GF bread, the lowest content of phytosterols was observed in samples that contained palm and coconut oils, followed by those that contained olive oil, while it was generally the highest in samples with sunflower oil (Fig. S9). This is in agreement with the increasing content of phytosterols in sunflower or soyabean> olive $>$ coconut or palm oils [25, 27, 28].

The richest cereals in stanols are rye, wheat, and corn [29]. Thus, the main sources of sitostanol in these bread samples were wheat and corn flours (Tables S3 and S4). The content of stanols decreases as flour refining increases. In fact, the stanols are concentrated in the outer layers of the kernel, whereas they are almost absent in the germ of these cereals [29]. This explains the higher and less variable contents of sitostanol in G samples (Table 1 and Fig. S8), which always included wheat flour (with a similar degree of refining) as ingredient, while GF samples included several ingredients derived from various GF cereals and pseudocereals (e.g., corn, rice, millet, teff, buckwheat, quinoa) with different refining degrees.

The difference in total phytosterols between $\mathrm{G}$ and GF samples was clear and significant (23.6 vs $11.3 \mathrm{mg} / 100 \mathrm{~g}$ WW, Table 1 and Fig. S10). This result deserves a comment because it is widely demonstrated that high contents of phytosterols in the diet reduce total- and LDL-cholesterol in plasma. However, as doses between 2 and $3 \mathrm{~g}$ of phytosterols and phytostanols are recommended for 2-3 weeks for a significant effect on these plasma cholesterol concentrations to be observed [30-32], the effect of the difference between $G$ and GF samples would be minimum in relation to this effect.

On the other hand, as commented above, the content of phytosterols in the samples depended on the ingredients used (mainly the added oil), but it also depended on the fat content of the sample (the higher the fat content, usually the higher the percentage of added oil). This can be observed in Fig. S9, in which one GF bread sample (GF 15) shows much higher content of phytosterols than the rest of samples that only declare sunflower oil in their list of ingredients. However, this sample (GF 15) also showed the highest fat content by far (Table S2) among these sunflower oil-containing samples. In addition, GF 15 sample was the only one declaring rice bran as ingredient and it is well known that crude rice bran oil is one of the richest crude oils in phytosterols [33]. Thus, apart from the added oils, other ingredients, such as rice bran, could show a significant effect on the phytosterols contents. In addition, because of its high phytosterol content, this sample was separated from the rest of samples containing only sunflower oil in Fig. 2 (upper left area of Fig. 2a). 


\section{Nutritional Information from Labeling: Comparison with the Analytical Results}

The nutritional information declared on the label of each sample is shown in Tables S5 and S6 (supplementary material). First of all, to evaluate the quality of the nutritional information declared on the labels, for each sample the moisture determined in our laboratory was compared with the moisture estimated from the nutrients declared on the label of the product. The estimation was carried by the following formula $\%$ moisture $=100-\%$ fat $-\%$ carbohydrates $-\%$ dietary fiber - \%protein - \%salt. This is a rough estimation that overestimates the moisture since the ash content (that was not provided in the labels) must be higher than the declared salt content. The comparison of these moisture values showed a great difference for two GF samples (GF 18, determined, 36.8\%, estimated, $14.1 \%$; GF 20, determined $44.0 \%$, estimated, $11.6 \%$ ). Thus, the macronutrients and energy declared for these two samples would be highly overestimated and consequently were not included in Table 3 (energy was respectively the 144 and $151 \%$ of the mean energy provided by the rest of GF samples). The rest of the samples showed much lower differences between the determined and the estimated moisture. For $\mathrm{G}$ samples $(n=14)$ differences were: mean $=$ $-2.06 \%$, median $=-2.15 \%$, minimum $=-4.40 \%$, maximum $=$ $0.92 \%$; and for GF samples $(n=18)$ : mean $=-0.02 \%$; median $=-0.05 \%$; minimum $=-4.53 \%$, maximum $=6.67 \%$.

From the nutritional information declared it was observed that the differences between $\mathrm{G}$ and GF samples were not significant for energy, carbohydrates and sugars, and significant for the rest of nutrition facts (Table 3). Fat, saturated fat, dietary fiber and salt were higher in GF samples, while protein was lower. The previous studies analyzing labeling information of white bread reported similar significant differences for fat, dietary fiber and protein $[2,5]$. However, for saturated fat Allen and Orfila [2] did not find a significant difference, while Fry et al. [5], as in our case, found higher saturated fat in GF white bread. None of these studies found a significant difference for salt content.

Our analytical results confirm that fat and salt were higher for GF samples. As both fat content and the mean SFA percentage were higher for GF samples (Tables 1 and 2), this group of samples must have on average higher saturated fat content. When the analytical results were compared with the declared

Table 3 Nutritional information declared on the labels of the gluten-containing and gluten-free samples, comparison with the analytical results (100 $\mathrm{g}$ of edible portion)

\begin{tabular}{|c|c|c|c|c|c|}
\hline \multirow[t]{2}{*}{ Label information } & \multicolumn{2}{|c|}{ Gluten-containing } & \multicolumn{3}{|l|}{ Gluten-free } \\
\hline & Mean \pm SD & Median & Mean \pm SD & Median & $P^{*}$ \\
\hline Energy (kcal) $(n=14$ vs 18$)$ & $254.3 \pm 8.88$ & 252.5 & $258.4 \pm 18.01$ & 255 & 0.837 \\
\hline Fat $(g)(n=14$ vs 18$)$ & $2.9 \pm 0.81$ & 3 & $5.3 \pm 1.94$ & 5.1 & $<0.001$ \\
\hline Saturated fat $(\mathrm{g})(n=14 v s$ 18) & $0.6 \pm 0.17$ & 0.5 & $1.2 \pm 0.85$ & 0.9 & 0.001 \\
\hline Carbohydrates (g) ( $n=14$ vs 18$)$ & $46.6 \pm 1.10$ & 46 & $48.1 \pm 7.25$ & 48.0 & 0.319 \\
\hline Sugars $(g)(n=14$ vs 18$)$ & $3.7 \pm 0.89$ & 3.8 & $3.3 \pm 2.40$ & 3.3 & 0.193 \\
\hline Dietary fiber (g) ( $n=11$ vs 12$)$ & $2.8 \pm 0.93$ & 2.9 & $4.7 \pm 2.92$ & 4.5 & 0.027 \\
\hline Protein $(\mathrm{g})(n=14$ vs 18$)$ & $9.2 \pm 0.40$ & 9 & $3.0 \pm 1.65$ & 2.4 & $<0.001$ \\
\hline Salt (g) $(n=14$ vs 20$)$ & $1.1 \pm 0.21$ & 1.2 & $1.5 \pm 0.43$ & 1.5 & 0.002 \\
\hline \multicolumn{6}{|c|}{ Analytical results and deviation relative to declared contents } \\
\hline Fat $(\mathrm{g})(n=14$ vs 20$)$ & $1.9 \pm 0.53$ & 1.7 & $3.6 \pm 1.57$ & 3.9 & 0.001 \\
\hline Deviation in $\mathrm{g}(n=14 v s 18)$ & $-0.93 \pm 0.51$ & -1.13 & $-1.79 \pm 0.94$ & -1.60 & 0.005 \\
\hline Salt $(\mathrm{g})(n=14$ vs 20$)$ & $1.1 \pm 0.19$ & 1.1 & $1.4 \pm 0.32$ & 1.3 & 0.020 \\
\hline Deviation in $\mathrm{g}(n=14$ vs 20$)$ & $-0.001 \pm 0.15$ & 0.021 & $-0.107 \pm 0.41$ & -0.009 & 0.500 \\
\hline \multicolumn{6}{|c|}{ Percentage contribution to reference nutrient intake (from analytical results) } \\
\hline Fat $(\%)(n=14$ vs 20$)$ & $2.8 \pm 0.75$ & 2.4 & $5.2 \pm 2.24$ & 5.6 & $<0.001$ \\
\hline Salt $(\%)(n=14$ vs 20$)$ & $19.1 \pm 3.11$ & 17.5 & $23.0 \pm 5.32$ & 22.1 & 0.020 \\
\hline
\end{tabular}

${ }^{*} P$-values for median comparisons between gluten-containing $(\mathrm{G})$ and gluten-free (GF) samples according to Mann-Whitney $U$ test

The number of samples used for the statistical analysis was different for each variable. For G samples $n$ was always 14, except for dietary fiber that was 11 , because dietary fiber content was not declared on the labels of three samples. For GF samples $n$ was 20 for analytical results and declared salt content, it was 18 for the declared energy and macronutrients, except for dietary fiber that was 12 because was not declared on the labels of six samples. The energy and macronutrients declared on the label of two GF samples are not reliable, since the moisture (\%) estimated from the nutrients declared greatly differs from moisture analytically determined (GF 18, determined, 36.8, estimated, 14.1; GF 20, determined 44.0, estimated, 11.6). For all samples the moisture was estimated by the following formula $\%$ moisture $=100-\%$ fat $-\%$ carbohydrates $-\%$ dietary fiber $-\%$ protein $-\%$ salt, and compared with the real moisture determined. Reference nutrient intakes for fat $70 \mathrm{~g}$ and for salt $6 \mathrm{~g}$ [35] 
nutritional information, we observed (Table 3) that determined fat was lower than the declared value and that the deviation was significantly higher for GF samples. Determined salt was lower than the declared value only for GF samples. In order to assess the deviations between determined and declared contents for each sample, the guidelines from the European Commission for the tolerances in these deviations were followed [34]. Only two $G$ samples exceeded the tolerance in deviation for salt (Table S5); while $10 \mathrm{GF}$ samples exceeded the tolerance in deviation for fat and seven for salt (Table S6). After this evaluation, it can be concluded that the quality of the nutritional information was low in 16 out of 20 GF samples; while only in two out of $14 \mathrm{G}$ samples (Tables S5 and S6). The contents declared in the nutritional labeling can be obtained from analysis but they are usually calculated from the known average values of the ingredients (from ingredient specification sheets) or from generally established and accepted data in the literature [35]. Thus, the variations in the raw materials, the effect of processing, nutrient stability and storage time and conditions can affect these values. Therefore, these deviations were not surprising since the GF breads have on average much more ingredients than G breads (Tables S3 and S4) and the calculation of the declared values has more sources of uncertainty. This problem was previously anticipated by Roman et al. [13], but not checked through analytical determinations.

The fat and salt content of the $G$ and GF samples contribute in a different proportion to the reference nutrient intakes set by the EU legislation [35] (Table 3).

\section{Conclusion}

Samples of GF sliced white sandwich bread had higher contents of sodium, fat, cholesterol and stigmasterol, and lower contents of campesterol, $\beta$-sitosterol, sitostanol and total phytosterols than $\mathrm{G}$ samples. The FA composition was also different between sample groups, being GF bread richer in MUFA and poorer in PUFA. Regarding the SFA, significant differences were observed for some concrete FA such as C8:0 and C10:0, with higher percentage in GF bread, or in C18:0, with a higher percentage in $\mathrm{G}$ bread. The differences between samples in sterol and fatty acid profiles depended on the ingredients used in their formulation.

In conclusion, the nutritional quality of GF bread varied according to the ingredients used in its preparation and might be lower than that of $\mathrm{G}$ bread. It could be discussed whether these differences in composition are sufficiently important from a nutritional point of view when GF bread is included in an adequate and balanced diet, but this discussion does not make much sense, because these differences in composition could be easily reduced or eliminated by changes in the formulation of GF bread. For instance, since 13 of the 20 GF samples did not contain cholesterol or only contained traces of this component, it is clear that
GF bread without cholesterol can be formulated. In fact, except in five GF samples where whole egg was used, cholesterol levels were practically negligible. Also, the reduction of sodium in GF samples can be feasible because 9 of the 20 GF samples had sodium content below $0.5 \mathrm{~g} / 100 \mathrm{~g} \mathrm{WW}$. On the other hand, only four of the $20 \mathrm{GF}$ samples declared the use of saturated fats (Table S4); however, the FA composition suggested that seven of the $20 \mathrm{GF}$ samples included fats such as coconut and palm oils (Figs. S3, S4 and S5). In addition, if we look at the composition of the GF samples 10 and 11, we see that their composition is very close to the average composition values of $G$ samples, therefore the reformulation of the GF bread is completely feasible. Of course, the reformulation is a task that can be more or less complicated based on the knowledge of the technological and nutritional functions of the ingredients and on empiric observations and experiments (usually, trial/error experiments until achieving good organoleptic characteristics, consumer acceptance and nutritional quality). In addition, it is also possible to educate coeliacs to use the ingredient list and nutrition information on the label to choose the highest quality breads, which also will push the industry to reformulation of GF products.

In addition, the comparison of the analytical results obtained in our laboratory for fat and salt content with the declared contents on the labels showed a much higher deviation for GF samples and it can be concluded that the quality of the nutritional information declared was lower in GF samples.

Acknowledgments To the Scientific and Technological Centers of the University of Barcelona for its technical assistance in the determination of the sodium content of the samples.

Author Contributions Experimental design: Alba Tres, Anna Gibert, Elisenda Vilchez, Francesc Guardiola; Sampling: Natalia Tarnovska, Elisenda Vilchez, Francesc Guardiola; Analytical determinations: Alba Tres, Natalia Tarnovska, Elisa Varona, Beatriz Quintanilla-Casas, Stefania Vichi, Francesc Guardiola; Statistical analysis and data interpretation: Alba Tres, Natalia Tarnovska, Elisa Varona, Beatriz QuintanillaCasas, Stefania Vichi, Francesc Guardiola; Manuscript draft preparation: Alba Tres, Natalia Tarnovska, Francesc Guardiola; Revision of the draft: Elisa Varona, Beatriz Quintanilla-Casas, Stefania Vichi, Anna Gibert, Elisenda Vilchez; Supervision: Alba Tres, Francesc Guardiola.

Funding Information This work was partially funded by the Associació de Celíacs de Catalunya. The study was also supported by the Spanish MICINN through JCI post-doctoral program (JCI-2012_13412) and RyC post-doctoral program (RYC-2017-23,601) granted to Alba Tres.

\section{Compliance with Ethical Standards}

Conflict of Interest The authors declare that they have no conflict of interest.

Open Access This article is licensed under a Creative Commons Attribution 4.0 International License, which permits use, sharing, adaptation, distribution and reproduction in any medium or format, as long as you give appropriate credit to the original author(s) and the source, provide a link to the Creative Commons licence, and indicate if changes were made. The images or other third party material in this article 
are included in the article's Creative Commons licence, unless indicated otherwise in a credit line to the material. If material is not included in the article's Creative Commons licence and your intended use is not permitted by statutory regulation or exceeds the permitted use, you will need to obtain permission directly from the copyright holder. To view a copy of this licence, visit http://creativecommons.org/licenses/by/4.0/.

\section{References}

1. Mustalahti K, Catassi C, Reunanen A, Fabiani E, Heier M, McMillan S, Murray L, Metzger MH, Gasparin M, Bravi E, Mäki (2010) The prevalence of celiac disease in Europe: results of a centralized, international mass screening project. Ann Med 42: 587-595. https://doi.org/10.3109/07853890.2010.505931

2. Allen B, Orfila C (2018) The availability and nutritional adequacy of gluten-free bread and pasta. Nutrients 10:1370. https://doi.org/ 10.3390/nu10101370

3. Calvo-Lerma J, Crespo-Escobar P, Martínez-Barona S, FornesFerrer V, Donat E, Ribes-Koninckx C (2019) Differences in the macronutrient and dietary fibre profile of gluten-free products as compared to their gluten-containing counterparts. Eur J Clin Nutr 73:930-936. https://doi.org/10.1038/s41430-018-0385-6

4. do Nascimento AB, Fiates GMR, dos Anjos A, Teixeira E (2014) Availability, cost and nutritional composition of gluten-free products. Brit Food J 116:1842-1852. https://doi.org/10.1108/BFJ-052013-0131

5. Fry L, Madden AM, Fallaize R (2018) An investigation into the nutritional composition and cost of gluten-free versus regular food products in the UK. J Hum Nutr Diet 31:108-120. https://doi.org/ 10.1111/jhn. 12502

6. Kulai T, Rashid M (2014) Assessment of nutritional adequacy of packaged gluten-free food products. Can J Diet Pract Res 75:186190. https://doi.org/10.3148/cjdpr-2014-022

7. Miranda J, Lasa A, Bustamante MA, Churruca I, Simon E (2014) Nutritional differences between a gluten-free diet and a diet containing equivalent products with gluten. Plant Foods Hum Nutr 69: 182-187. https://doi.org/10.1007/s11130-014-0410-4

8. Missbach B, Schwingshack1 L, Billmann A, Mystek A, Hickelsberger M, Bauer G, König J (2015) Gluten-free food database: the nutritional quality and cost of packaged gluten-free foods. Peer J 3:e1337. https://doi.org/10.7717/peerj.1337

9. Morreale F, Angelino D, Pellegrini N (2018) Designing a scorebased method for the evaluation of the nutritional quality of the gluten-free bakery products and their gluten-containing counterparts. Plant Foods Hum Nutr 73:154-159. https://doi.org/10.1007/ s11130-018-0662-5

10. Tres A, Vichez E, Roger E, Gibert A, Vichi S, Guardiola F (2017) Comparative study of the composition of products with and without gluten in the Spanish market-evaluation of bibliographic data. Libifood web. https://libifood.wordpress.com/projectes/oxidacioestabilitat-i-qualitat-projectes/qualitat-nutricional-dels-aliments/ qualitat-nutricional-de-productes-sense-gluten/. Accessed 12 Apr 2020

11. Wu JHY, Neal B, Trevena H, Crino M, Stuart-Smith W, FaulknerHogg K, Yu Louie JC, Dunford E (2015) Are gluten-free foods healthier than non-gluten-free foods? An evaluation of supermarket products in Australia. Brit J Nutr 114:448-454. https://doi.org/10. 1017/S0007114515002056

12. Capriles VD, Arêas JAG (2014) Novel approaches in gluten-free breadmaking: interface between food science, nutrition, and health. Compr Rev Food Sci Food Saf 13:871-890. https://doi.org/10. 1111/1541-4337.12091
13. Roman L, Belorio M, Gomez M (2019) Gluten-free breads: the gap between research and commercial reality. Compr Rev Food Sci Food Saf 18:690-702. https://doi.org/10.1111/1541-4337.12437

14. Gibert A, Espadaler M, Canela MA, Sánchez A, Vaqué C, Rafecas M (2006) Consumption of gluten-free products: should the threshold value for trace amounts of gluten be at 20,100 or 200 p.p.m.? Eur J Gastroenterol Hepatol 18:1187-1195. https://doi.org/10. 1097/01.meg.0000236884.21343.e4

15. De Marchi S, Chiarioni G, Prior M, Arosio E (2013) Young adults with coeliac disease may be at increased risk of early atherosclerosis. Aliment Pharmacol Ther 38:162-169. https://doi.org/10.1111/ apt. 12360

16. Wei L, Spiers E, Reynolds N, Walsh S, Fahey T, Macdonald TM (2007) The association between coeliac disease and cardiovascular disease. Aliment Pharmacol Ther 27:514-519. https://doi.org/10. 1111/j.1365-2036.2007.03594.x

17. West J, Logan RFA, Card TR, Smith C, Hubbard R (2004) Risk of vascular disease in adults with diagnosed coeliac disease: a population-based study. Aliment Pharmacol Ther 20:73-79. https://doi.org/10.1111/j.1365-2036.2004.02008.x

18. Emilsson L, Lebwohl B, Sundström J, Ludvigsson JF (2015) Cardiovascular disease in patients with coeliac disease: a systematic review and meta-analysis. Digest Liver Dis 47:847-852. https:// doi.org/10.1016/j.dld.2015.06.004

19. Heikkilä K, Koskinen OA, Agarwal A, Tikkinen KAO, Mäki M, Kaukinen K (2015) Associations of coeliac disease with coronary heart disease and cerebrovascular disease: a systematic review and meta-analysis. Nutr Metab Cardiovasc Dis 25:816-831. https://doi. org/10.1016/j.numecd.2015.05.004

20. Brar P, Kwon GY, Holleran S, Bai D, Tall AR, Ramakrishnan R, Green PHR (2006) Change in lipid profile in celiac disease: beneficial effect of gluten-free diet. Am J Med 119:786-790. https://doi. org/10.1016/j.amjmed.2005.12.025

21. Zanini B, Mazzoncini E, Lanzarotto F, Ricci C, Cesana BM, Villanacci V, Lanzini A (2013) Impact of gluten-free diet on cardiovascular risk factors, a retrospective analysis in a large cohort of coeliac patients. Digest Liver Dis 45:810-815. https://doi.org/10. 1016/j.dld.2013.04.001

22. Potter MDE, Brienesse SC, Walker MM, Boyle A, Talley NJ (2018) Effect of the gluten- free diet on cardiovascular risk factors in patients with coeliac disease: a systematic review. J Gastroen Hepatol 33:781-791. https://doi.org/10.1111/jgh.14039

23. Kim HS, Demyen MF, Mathew J, Kothari N, Feurdean M, Ahlawat SK (2017) Obesity, metabolic syndrome, and cardiovascular risk in gluten-free followers without celiac disease in the United States: results from the national health and nutrition examination survey 2009-2014. Dig Dis Sci 62:2440-2448. https://doi.org/10.1007/ s10620-017-4583-1

24. Lebwohl B, Cao Y, Zong G, Hu FB, Green PHR, Neugut AI, Rimm EB, Sampson L, Dougherty LW, Giovannucci E, Willett WC, Sun Q, Chan AT (2017) Long term gluten consumption in adults without celiac disease and risk of coronary heart disease: prospective cohort study. BMJ 357:j1892. https://doi.org/10.1136/bmj.j1892

25. FAO-WHO (1999) Codex standard for named vegetable oils (CODEX-STAN 210-1999). Adopted 1999, revisions 2001, 2003, 2009, amendments 2005, 2011, 2013, tables 1 and 3 . Available online: http://www.fao.org/docrep/004/y2774e/ y2774e04.htm. Accessed 12 Apr 2020

26. Souci S, Fachmann W, Kraut H (2008) Food composition and nutrition tables, 7th edn. Medpharm, Stuttgart; and CRC Press, Boca Ratón, pp 14-16 169-170, 338-339, 344-345

27. Gunstone FD (2011) Vegetable oils in food technology composition, properties and uses, 2nd edn. Wiley-Blackwell, Chichester, $\mathrm{p}$ 253

28. Phillips KM, Ruggio DM, Toivo JI, Swank MA, Simpkins AH (2002) Free and esterified sterol composition of edible oils and fats. 
J Food Comp Anal 15:123-142. https://doi.org/10.1006/jfca.2001. 1044

29. Piironen V, Lampi A-M (2004) Occurrence and levels of phytosterols in foods. In: Dutta P (ed) Phytosterols as functional food components and nutraceuticals. Marcel Dekker, New York, chapter 1 , pp $1-32$

30. EFSA Panel on Dietetic Products, Nutrition and Allergies (2012) Scientific opinion on the substantiation of a health claim related to 3 $\mathrm{g} /$ day plant sterols/stanols and lowering blood LDL-cholesterol and reduced risk of (coronary) heart disease pursuant to article 19 of regulation (EC) no 1924/2006. EFSA J 10(5):2693

31. Musa-Veloso K, Poon TH, Elliot JA, Chung C (2011) A comparison of the LDL- cholesterol lowering efficacy of plant stanols and plant sterols over a continuous dose range: results of a metaanalysis of randomized, placebo-controlled trials. Prostag Leukotr Ess 85:9-28. https://doi.org/10.1016/j.plefa.2011.02.001

32. Ras RT, Geleijnse JM, Trautwein EA (2014) LDL-cholesterollowering effect of plant sterols and stanols across different dose ranges: a meta-analysis of randomised controlled studies. Brit $\mathrm{J}$ Nutr 112:214-219. https://doi.org/10.1017/S0007114514000750

33. Miettinen TA, Gylling H (2004) Prospects of increasing nutritional phytosterol levels in plants. In: Dutta P (ed) Phytosterols as functional food components and nutraceuticals. Marcel Dekker, New York, chapter 12, pp 431-439

34. Guidance document for competent authorities for the control of compliance with EU legislation on the provision of food information to consumers. December 2012. https://ec.europa.eu/food/sites/ food/files/safety/docs/labelling_nutrition-vitamins_mineralsguidance_tolerances_1212_en.pdf. Accessed 12 Apr 2020

35. European Parliament and Council of the European Union (2011) Regulation (EU) 1169/2011 of 25 October 2011 on the provision of food information to consumers. OJEU L304:18-63

Publisher's Note Springer Nature remains neutral with regard to jurisdictional claims in published maps and institutional affiliations. 